\title{
The influence of a radiated heat exchanger surface on heat transfer
}

\section{SŁAWOMIR MOREL ${ }^{1}$}

Czestochowa University of Technology, Industrial Furnaces Department and Environmental Protection, al. Armii Krajowej 19, 42-200 Czestochowa, Poland

\begin{abstract}
The experiment leads to establish the influence of radiated surface development heat exchangers on the values of heat flux transferred with water flowing through the exchangers and placed in electric furnace chamber. The values of emissivity coefficients are given for the investigated metal and ceramic coatings. Analytical calculations have been made for the effect of the heating medium (flame) - uncoated wall and then heating medium (flame) - coated wall reciprocal emissivity coefficients. Analysis of the values of exchanged heat flux were also realized. Based on the measurement results for the base coating properties, these most suitable for spraying the walls of furnaces and heat exchangers were selected, and determined by the intensification of heat exchange effect. These coatings were used to spray the walls of a laboratory waste-heat boiler, and then measurements of fluxes of heat absorbed by the cooling water flowing through the boiler tubes covered with different type coatings were made. Laboratory tests and calculations were also confirmed by the results of full-scale operation on the metallurgical equipment.
\end{abstract}

Keywords: Heat exchager; Reciprocal emissivity coefficient

\section{Nomenclature}

$F_{s} \quad$ - boiler surface, $\mathrm{m}^{2}$

$k_{p} \quad-$ heat resistance, $\mathrm{mK} / \mathrm{W}$

$T_{g} \quad$ - exhaust gas temperature, $\mathrm{K}$

$T_{s} \quad-\quad$ boiler surface temperature, $\mathrm{K}$

$x_{w} \quad-\quad$ layer thickness, $\mathrm{m}$

${ }^{1}$ E-mail: morel@wip.pcz.pl 
$x_{\text {matrix }} \quad-\quad$ matrix thickness, $\mathrm{m}$

$x_{s} \quad-\quad$ boiler wall thickness, m

\section{Greek symbols}

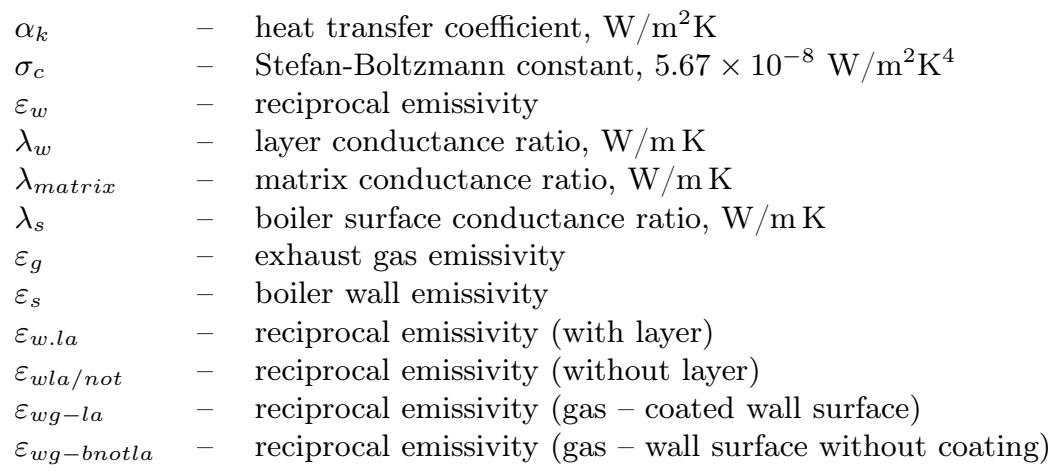

\section{Introduction}

Main aim of the article is to select a specific sort of coating based of mechanical, thermal and physical properties of analyzed coatings in order to its application in the heat exchanger. Furnaces, boilers, recuperators and other large-sized thermal equipment operate at increased or high temperatures. Their effectiveness is mostly determined by radiant heat exchange which depends also on the values of emissivity and thermal conductivity coefficients. Such properties might be varied within a broad range of changes in designing of the radiated walls coatings with desirable surface roughness and structure porosity, i.e., the parameters which are highly dependent on the coating type, materials grain-size, grain fraction in the coating used, as well as on the parameters of the plasma spraying process [1-3].

Regarding the intended thermal tasks of coatings sprayed on the radiated wall surfaces of furnaces, heat exchangers, and other thermal equipment, the coatings can be classified into the following two basic groups:

A - coatings that absorb thermal radiation and conduct heat towards the substrate, and

B - coatings that emit thermal radiation from the coating surface.

The A group coatings should be characterized by large open porosity, i.e., developed surface that produces a high ability of absorbing heat, and by a large value of thermal conductivity coefficient $-\lambda$. They are sprayed, for example, on the radiated wall surfaces of recuperators, or boilers, with the 
aim of increasing the ability to absorb heat from the radiating flame, or combustion gases, and transfered to the heated media (such as air, water, steam, etc.).

The basic features of the B group coatings are: absorption of radiation on the coating surface and the emission of heat towards the heated charge, with the essential condition being met at the same time that the heat 'accumulated' on the coating surface should not penetrate inside the coating, but only increase the surface temperature instead. Thus, these coatings should also be characterized by high insulating power and be sufficiently thick [4-5].

They are sprayed on the walls and roofs of furnaces, and particularly those periodically operating, and also on the walls of flues installed after the heating furnaces, with recuperators incorporated in those flues.

The A and B group of coatings that intensify the absorption of heat from the flame and from the stream of (combustion) gas leaving the working spaces of furnaces, and heat exchangers, give as a consequence a decrease in the temperature of the combustion gas exhausted to the chimney (heat recovery) [6-7].

\section{Absorptivity of materials and coatings}

The exchanged heat flux depends on the value of reciprocal emissivity coefficient which is a function of the emissivity coefficients of heating and heated media. The industry commonly uses numerous methods of rendering high emissivity to heating media, such as flame carburization [1,8]. Less known and less commonly used are the methods of imparting high ability of thermal radiation absorption and emission to the walls and roofs of furnaces and flues, and to the walls of heat exchangers.

Variation of the values of heat absorption and emission coefficients for materials commonly used for the assembly of furnaces and (metal and ceramic) thermal equipment and coatings are shown in Fig. 1. It is easy to see that the absorptivity of metals polished (e.g., the tight wall of a wasteheat boiler) grows linearly with increasing temperature, while nonmetals exhibit the reverse trend [1]. It also follows that the emissivity coefficient of ceramic and (coarse) cermet coatings has a high and constant value. The depth of radiant energy penetration into the surface is determined by the electric properties of the material. High electric-conductivity materials are penetrated by radiation to a small depth, the major part of the radiation 


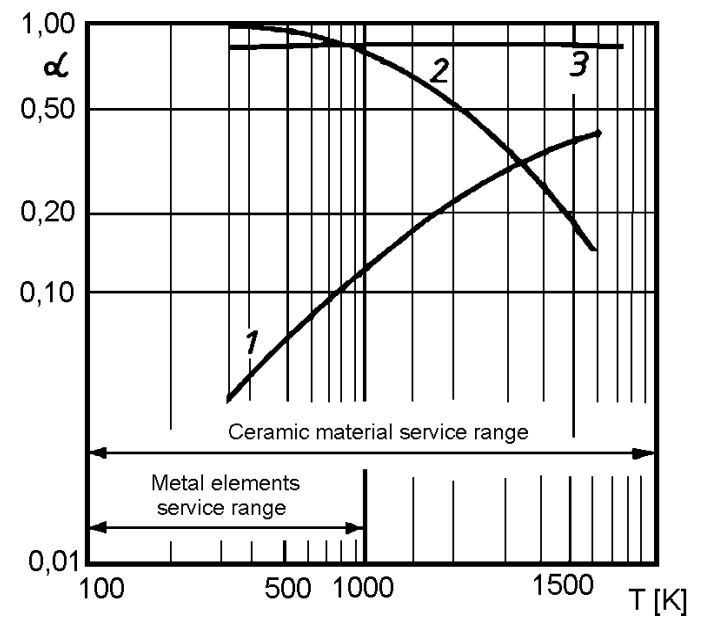

Figure 1: Variation of surface absorptivity and emissivity depending on the temperature of bodies for different materials [1]: 1 - metal, 2 - nonmetal, 3 - coating (coarse - ceramic or cermet).

being reflected.

However dielectric materials, which electric conductivity is small, are deeply penetrated by radiant energy, which main part will be absorbed. Pure nonmetallic surfaces have a low value of absorptivity coefficient. Surface roughness, impurities, and corrosion increase the value of absorptivity, and thick oxide layers may cause a substantial increase in $\varepsilon$ so that its value is similar to that of dielectrics (i.e., more than 0.7).

According to the complexity of absorption and emission as well as the flow of heat through the coatings, and the reason that processes are dependent on various parameters, there are no equations for the calculation of emissivity $\varepsilon$ and conductance ratio $\lambda$ values as a function of, for example, coating type, spraying parameters, which would make it possible to design a coating type with predetermined properties.

Because of that there is a need to develop methods and apparatus for the examination of the emissivity and thermal conductivity of multilayer coatings, testing the thermal parameters of the coatings, and selecting the coatings which should be selected for spraying on the walls of furnaces, heat exchangers, and other equipment improving their efficiency. The results of the investigation of coating properties are mentioned in paper [2,10-13]. 


\section{Effect of reciprocal emissivity coefficient on the amount of heat absorbed}

The basis for the considerations within the subject specified above is formula, which defines the flux of heat exchanged between the heating medium and the wall surface of furnaces or thermal equipment with a coating applied

$$
F_{s} \alpha_{k}\left(T_{g}-T_{s}\right)+F_{s} \sigma_{c} \varepsilon_{w}\left(T_{g}^{4}-T_{s}^{4}\right)=F_{s} k_{p}\left(T_{s}-T_{n}\right),
$$

The heat resistance, $k_{p}$, across the wall is described by the relation

$$
\frac{1}{k_{p}}=\frac{x_{w}}{\lambda_{w}}+\frac{x_{\text {matrix }}}{\lambda_{\text {matrix }}}+\frac{x_{s}}{\lambda_{s}}+\frac{1}{\alpha_{w}},
$$

Assuming that the combustion gas is a grey the reciprocal absorptivity, $\varepsilon_{w}$, can be defined as

$$
\frac{1}{\frac{1}{\varepsilon_{g}}+\frac{1}{\varepsilon_{s}}-1}=\varepsilon_{w}
$$

Substituting (1a) and (1b) into Eq. (1), the following equation is obtained:

$F_{s} \alpha_{k}\left(T_{g}-T_{s}\right)+F_{s} \sigma_{c} \frac{1}{\frac{1}{\varepsilon_{g}}+\frac{1}{\varepsilon_{s}}-1}\left(T_{g}^{4}-T_{s}^{4}\right)=F_{s} \frac{\left(T_{s}-T_{n}\right)}{\frac{x_{w}}{\lambda_{w}}+\frac{x_{\text {matrix }}}{\lambda_{\text {matrix }}}+\frac{x_{s}}{\lambda_{s}}+\frac{1}{\alpha_{w}}}$.

The results obtained with the above formulas show that the rational utilization of heat from heating media (such as flames or combustion gases) is determined by high temperature of the heating media, high emissivity of the heating media and walls (of furnaces and equipment) taking part in the heat exchange, and high thermal conductivity or insulating power of the walls participating in the heat exchange. To evaluate the influence of the wall emissivity coefficient, $\varepsilon_{l a}$, on the variation reciprocal emissivity coefficient, $\varepsilon_{s}$, calculations according to relationship (1b) were realized by taking the constant value of $\varepsilon_{g}=0.40$. The value of coefficient $\varepsilon_{l a}$ was assumed in the range from 0.20 for brightened metals, through $0.55-0.65$ for refractory materials, up to 0.95 for coatings made from high-melting metal black oxides.

The calculations of heating medium - uncoated metal wall reciprocal emissivity coefficient $\left(\varepsilon_{w . l a / n o t}\right)$ were made, and then the reciprocal emissivity of the heating medium - coated wall system $\left(\varepsilon_{w . l a}\right)$ was calculated taking the value of $\varepsilon_{l a}=0.90$, followed by determining the value of the ratio $\frac{\varepsilon_{w . l a}}{\varepsilon_{w . l a / n o t}}$. 
For the tight metal boiler wall or for recuperator segment tubes (generally - for the membrane heat exchanger), $\varepsilon_{l a}=0.30$ and $\varepsilon_{g}=0.40$ were assumed. The value of uncoated wall reciprocal emissivity coefficient $\left(\varepsilon_{w . l a / n o t}\right)$ as calculated from formula $(1 \mathrm{~b})$ is:

$$
\varepsilon_{w . l a / n o t}=\frac{1}{\frac{1}{0.40}+\frac{1}{0.30}}=0.207 .
$$

For the same metal exchanger surface, but with the sprayed coating with the emissivity coefficient value of $\varepsilon_{l a}=0.90$, the value of reciprocal emissivity coefficient (as calculated from formula (1b)) is:

$$
\varepsilon_{w . l a}=\frac{1}{\frac{1}{0.40}+\frac{1}{0.90}}=0.383 .
$$

The value of the flame-coated wall reciprocal emissivity coefficient to flameuncoated wall reciprocal emissivity coefficient ratio is:

$$
\frac{\varepsilon_{w \cdot l a}}{\varepsilon_{w / l a / n o t}} \cong 1.851
$$

The obtained result show $85 \%$ increment in the amount of heat absorbed by the metal exchanger surface with the sprayed coating of the assumed value of $\varepsilon_{l a}=0.90$.

For the specified values of coefficients of emissivity, i.e., for:

- metals with $\varepsilon_{l a}$ change ranging from 0.20 through 0.30 up to 0.40 ,

- refractory materials with $\varepsilon_{\text {lar }}$ change ranging from 0.55 to 0.65 ,

- coatings with $\varepsilon_{l a}$ change ranging from 0.70 to 0.95 ,

the value of the ratio was calculated as the reciprocal emissivity coefficients of the coatings divided by:

- reciprocal emissivity of the metal walls - Tab. $1-\frac{\varepsilon_{w \cdot g-l a}}{\varepsilon_{w g-l a / n o t}}$

- reciprocal emissivity of the ceramic walls - Tab. $2-\frac{\varepsilon_{w \cdot g-l a}}{\varepsilon_{w g-c e r}}$.

The above results show how big is the effect of the coating on increasing the absorption of heat by the radiated wall surfaces both of metal - Tab. 1, and of ceramic materials - Tab. 2 .

The results have significant importance for the case of indirect heating of furnace and heat exchanger walls, and for the heating of recuperator tubes, 
particularly their wall-side (rear) circuits, by heat absorbed and emitted through ceramic flue walls. The wall-side tube circuits are reheated by neat absorbed and emitted by the ceramic walls with bi-layer coatings applied having high emissivity and low thermal conductivity. It results from Tab. 1 that, for example, for the tight metal wall of a waste-heat boiler (of tubefin-tube type) with the assumed value of $\varepsilon_{l a}=0.30$, after covering this wall with layer of the value of $\varepsilon_{l a}=0.95$ and calculating the analyzed ratio, the value $\frac{\varepsilon_{w g-l a}}{\varepsilon_{w g-l a / n o t}}=1.893$, which means nearly a $90 \%$ increase in the amount of heat absorbed by the boiler walls.

\section{Coatings for spraying boilers and recuperators}

Reciprocal emissivity coefficient occurring in formula (1b) has a decisive influence on the amount of heat exchanged by radiation. When the effect mentioned is more intensive, the lower is the absorption ability of the radiated wall (before spraying the coating). Hence, in the operation of equipment with metal walls, the presence of coatings with a high value of $\varepsilon$ substantially increases the flux of exchanged heat [14-17].

The achievement of intensive heat exchange in boilers and recuperators is possible due to the presence of coatings with high emissivity and high thermal conductivity on their walls. The intensification of heat exchange and charge heating in the furnace chambers is possible by the presence of the bi-layer coating which is composed of a layer with high heat absorptivity and emissivity and an insulating layer with low thermal conductivity. The produced bi-layer coating with such a structure allows for heat concentration within the emission layer and also prevents the heat from flowing to the deeper layers of furnace walls and roofs, thereby reducing the heat losses through the walls. Some thermal and mechanical properties of cermetallic coatings made on the basis of aluminium, chromium, and zirconium oxides with the addition of $\mathrm{NiAl}$, and of $\mathrm{Cr}_{3} \mathrm{C}_{2}+\mathrm{NiAl}$ coatings are shown in Fig. 2.

The coatings made from the mixtures of chromium oxide with nickel aluminide came second with over 50 scores. The third position was occupied by the coatings from the mixtures of aluminium oxide with nickel aluminide. The coatings made from the mixtures of $\mathrm{ZrO}_{2}$ with NiAl proved to be unsuitable for spraying boilers, recuperators, etc.

The above mentioned coatings were used to spray the radiated walls of heat exchangers, and then the measurements of their effect on the heat flux values were taken. 
Table 1: The value of coating reciprocal emissivity coefficients to the reciprocal emissivities of the metal walls.

Heating Medium Emissivity

Metal Wall Emissivity

Calculated reciprocal emissiv-

ity of the heating medium

metal wall system

Emissivity of Coatings

ity of the heating medium -

coated wall system

\begin{tabular}{|l|l|l|l|l|l|l|l|l|l|l|l|l|l|l|l|l|}
\hline $\begin{array}{l}\text { Ratio of reciprocal Emissivity } \\
\text { Coefficients }\end{array}$ & $\frac{\varepsilon_{w g-l a}}{\varepsilon_{w g-s}}$ & 2.292 & 2.364 & 2.429 & 2.489 & 2.546 & 1.704 & 1.758 & 1.806 & 1.851 & 1.893 & 1.412 & 1.456 & 1.496 & 1.532 & 1.568 \\
\hline
\end{tabular}

Table 2: The value of the coating reciprocal emissivity coefficients to the reciprocal emissivities of the ceramic walls.

\begin{tabular}{|c|c|c|c|c|c|c|c|c|c|c|c|c|c|c|c|c|}
\hline Heating Medium Emissivity & $\varepsilon_{g}$ & \multicolumn{15}{|c|}{0.40} \\
\hline Ceramic Wall Emissivity & $\varepsilon_{s-c e r}$ & \multicolumn{5}{|c|}{0.55} & \multicolumn{5}{|c|}{0.60} & \multicolumn{5}{|c|}{0.65} \\
\hline $\begin{array}{l}\text { Calculated reciprocal emissiv- } \\
\text { ity of the heating medium - ce- } \\
\text { ramic wall system }\end{array}$ & $\varepsilon_{w g-s c e r}$ & \multicolumn{5}{|c|}{0.301} & \multicolumn{5}{|c|}{0.316} & \multicolumn{5}{|c|}{0.329} \\
\hline Emissivity of Coatings & $\varepsilon_{\text {pow }}$ & 0.75 & 0.80 & 0.85 & 0.90 & 0.95 & 0.75 & 0.80 & 0.85 & 0.90 & 0.95 & 0.75 & 0.80 & 0.85 & 0.90 & 0.95 \\
\hline $\begin{array}{l}\text { Calculated reciprocal emissiv- } \\
\text { ity of the heating medium - } \\
\text { coated wall system }\end{array}$ & $\varepsilon_{w g-p o w}$ & 0.353 & 0.364 & 0.374 & 0.383 & 0.392 & 0.353 & 0.364 & 0.374 & 0.383 & 0.392 & 0.353 & 0.364 & 0.374 & 0.383 & 0.392 \\
\hline $\begin{array}{l}\text { Ratio of reciprocal Emissivity } \\
\text { Coefficients }\end{array}$ & $\frac{\varepsilon_{w g-l a}}{\varepsilon_{w g-c e r}}$ & 1.172 & 1.209 & 1.243 & 1.272 & 1.302 & 1.117 & 1.151 & 1.184 & 1.212 & 1.141 & 1.073 & 1.106 & 1.137 & 1.164 & 1.191 \\
\hline
\end{tabular}




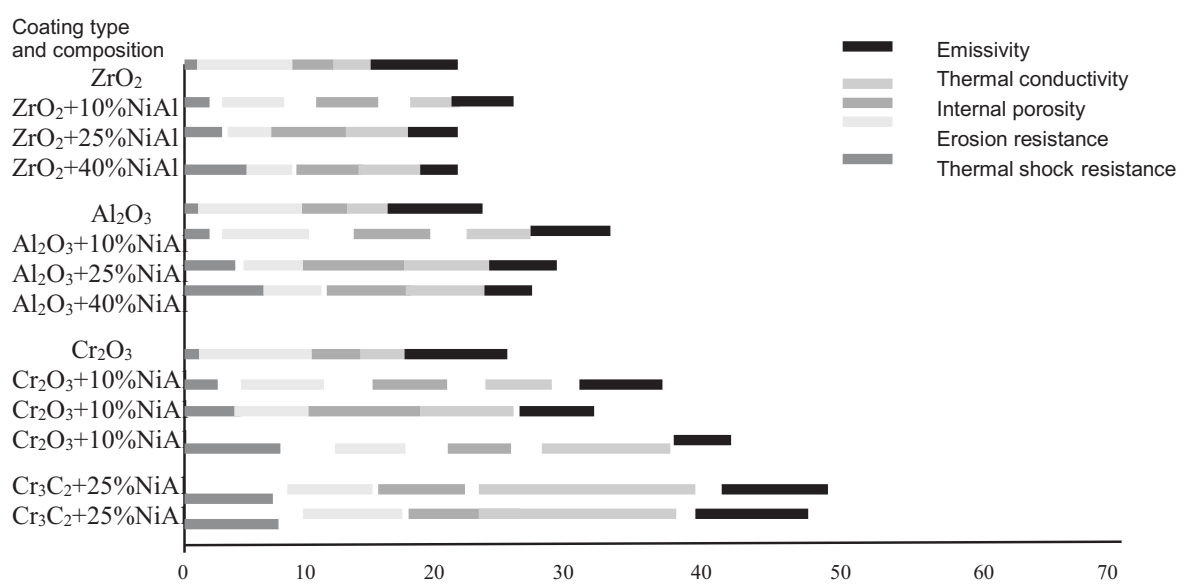

Figure 2: Conventional score evaluation of the stability of coatings sprayed on the walls of boilers and recuperators.

\section{Testing stand and the measurement methods}

A schematic of the stand on which tests were carried out on the effect of the coatings sprayed on the radiated tight walls of a boiler on the amount of heat absorbed by water flowing in the system of tubes is shown in Fig. 3.

The model boiler is composed of two 600-mm-diameter and 2300-mmhigh semicylinders built in a tube-fin-tube arrangement (38-mm-diameter $\mathrm{x} 4$ tubes, and $20 \mathrm{x} 4$ fins). With using a diffusion burner, natural gas was burnt producing a luminous flame up to the $3 / 4$ of the boiler's height. Measurements of the heat-exchange characterizing parameters were started after the thermal balance had been reached. The tests were performed in two stages, each of the stages including three measurement series.

For stage I, two sections with coatings sprayed on their surfaces were used: section 1 - $\mathrm{NiAl}$ (reference state of measurements); and section 2 $\mathrm{Cr}_{3} \mathrm{C}_{2}+25 \% \mathrm{NiAl}$.

For stage 2, section 1 ( NiAl) and section 3 were used, the latter being sprayed with the $\mathrm{Cr}_{2} \mathrm{O}_{3}+40 \% \mathrm{NiAl}$ coating. The results are shown in Fig. 4 and in Tab. 3. 


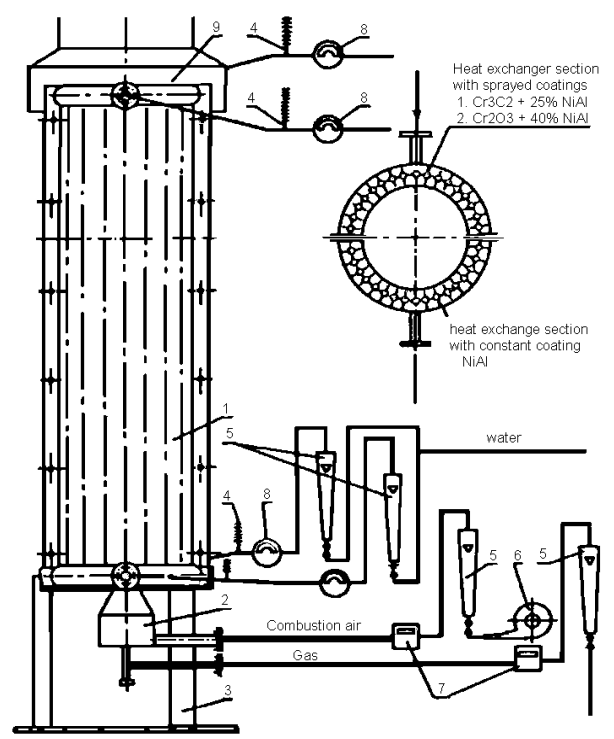

Figure 3: A schematic view of the installation of a model heat exchanger used for testing of the heat absorption effect of the coating types on the heat exchange in the waste-heat boiler: 1 - model waste-heat boiler, 2 - burner, 3 - stand, 4 thermocouple - recorder, 5 - rotameter, 6 - fan, 7 - gas meter, 8 - water meter, 9 - hood with a combustion-gas exhaust and a thermocouple for the measurement of combustion-gas temperature.

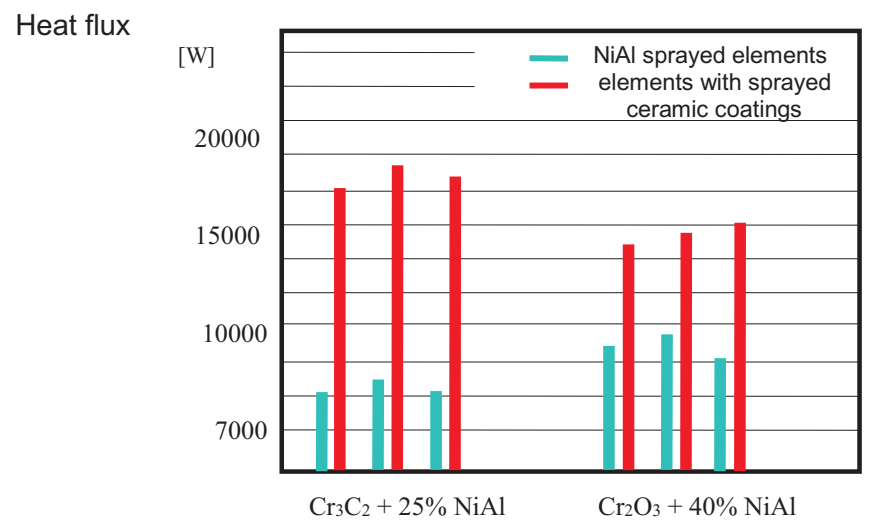

Figure 4: Effectiveness of cermet coatings on the flux of heat absorbed by the boiler. 
Table 3: Parameters of water streams flowing through the boiler sections.

\begin{tabular}{|c|c|c|c|c|c|c|c|c|c|}
\hline \multirow{4}{*}{$\begin{array}{l}\text { Stage } \\
\text { series }\end{array}$} & \multirow{4}{*}{$\begin{array}{c}\text { Coating } \\
\text { type }\end{array}$} & \multirow{2}{*}{\multicolumn{2}{|c|}{\begin{tabular}{|c|} 
Burner feeding \\
parameters
\end{tabular}}} & \multicolumn{4}{|c|}{ Flowing water parameters } & \multirow{3}{*}{\multicolumn{2}{|c|}{$\begin{array}{c}\text { Heat flux carried } \\
\text { with water }\end{array}$}} \\
\hline & & & & \multicolumn{2}{|c|}{ Temperature } & \multirow{3}{*}{$\begin{array}{c}\begin{array}{c}\text { Temperature } \\
\text { increase }\end{array} \\
{ }^{\circ} \mathrm{C}\end{array}$} & \multirow{3}{*}{\begin{tabular}{|c}
$\begin{array}{c}\text { Mass } \\
\text { flux }\end{array}$ \\
$\mathrm{g} \mathrm{s}^{-1}$
\end{tabular}} & & \\
\hline & & Gas & Air & Inlet & Outlet & & & & \\
\hline & & $\mathrm{m}^{3} \mathrm{~h}^{-1}$ & $\mathrm{~m}^{3} \mathrm{~h}^{-1}$ & ${ }^{\circ} \mathrm{C}$ & ${ }^{\circ} \mathrm{C}$ & & & $\mathrm{W}$ & $\%$ \\
\hline 1 & 2 & 3 & 4 & 5 & 6 & $\overline{7}$ & 8 & 9 & 10 \\
\hline \multirow[t]{2}{*}{ I.1 } & $\mathrm{NiAl}$ & 2 & 18 & 11.1 & 24.9 & 13.8 & 164 & 9460 & 100 \\
\hline & $\mathrm{Cr}_{3} \mathrm{C}_{2}+25 \% \mathrm{NiAl}$ & & & 11.1 & 30.9 & 19.8 & 210 & 17380 & 184 \\
\hline \multirow[t]{2}{*}{ I.2 } & $\mathrm{NiAl}$ & 2 & 18 & 11.1 & 26.0 & 14.2 & 160 & 9496 & 100 \\
\hline & $\mathrm{Cr}_{3} \mathrm{C}_{2}+25 \% \mathrm{NiAl}$ & & & 11.1 & 32.6 & 20.8 & 216 & 18779 & 198 \\
\hline \multirow[t]{2}{*}{ I.3 } & $\mathrm{NiAl}$ & 2 & 18 & 11.1 & 25.5 & 14.5 & 182 & 11031 & 100 \\
\hline & $\mathrm{Cr}_{3} \mathrm{C}_{2}+25 \% \mathrm{NiAl}$ & & & 11.1 & 30.5 & 19.5 & 226 & 18421 & 167 \\
\hline \multirow[t]{2}{*}{ II.4 } & $\mathrm{NiAl}$ & 2 & 18 & 11.1 & 25.0 & 13.9 & 176 & 10226 & 100 \\
\hline & $\mathrm{Cr}_{3} \mathrm{C}_{2}+40 \% \mathrm{NiAl}$ & & & 11.1 & 30.3 & 19.1 & 189 & 15089 & 148 \\
\hline \multirow[t]{2}{*}{ II. 5} & $\mathrm{NiAl}$ & 2 & 18 & 11.1 & 26.1 & 14.7 & 170 & 10445 & 100 \\
\hline & $\mathrm{Cr}_{3} \mathrm{C}_{2}+40 \% \mathrm{NiAl}$ & & & 11.1 & 29.8 & 18.4 & 193 & 14844 & 132 \\
\hline \multirow[t]{2}{*}{ II. 6} & $\mathrm{NiAl}$ & 2 & 18 & 11.1 & 25.1 & 14.1 & 189 & 11140 & 100 \\
\hline & $\mathrm{Cr}_{3} \mathrm{C}_{2}+40 \% \mathrm{NiAl}$ & & & 11.1 & 30.4 & 19.4 & 180 & 16637 & 149 \\
\hline
\end{tabular}

\section{Results analysis}

In the first stage of the measurements carried out, the most favourable results were obtained from the second measurement series. The temperature of water flowing to the both sections, i.e. to section 1 with the NiAl coating and to section 2 with the $\mathrm{Cr}_{2} \mathrm{O}_{3}+25 \% \mathrm{NiAl}$ coating was $11.8^{\circ} \mathrm{C}$, whereas the water temperature at the outlet of the section system was: from section $1-26.0{ }^{\circ} \mathrm{C}$, and from section $2-32.6{ }^{\circ} \mathrm{C}$. The water temperature increase was, respectively: in section $1-14.2^{\circ} \mathrm{C}$, and in section $2-20.8^{\circ} \mathrm{C}$. With the water flow values as per Tab. 4, column 8 , row 2 , the fluxes of heat carried away with the heated water reached the following values:

- from section 1 sprayed with the NiAl coating - $9496 \mathrm{~W}(100 \%)$,

- from section 2 sprayed with the $\mathrm{Cr}_{2} \mathrm{O}_{3}+25 \% \mathrm{NiAl}$ coating - 18779 W $(198 \%)$

which is roughly twice as high as the values obtained from section 1 sprayed with NiAl coating. This doubling of the amount of heat carried with water, obtained as the result of spraying section 2 with the carbide coating (with the high value of $Q_{\alpha} / Q_{\varepsilon}$ and the high value of $\lambda_{\text {pow }}$ ) clearly confirms the 
suitability of this kind of coating for intensifying the processes of heat absorption from heating media. The absorption by water of almost doubled amount of heat from the flame and from the flowing combustion gas indicates high efficiency of heat utilization in the working space of the exchanger sprayed with absorptive-conductive coatings.

Table 4: Comparison of laboratory and industrial scale results for the various coating.

\begin{tabular}{|c|c|c|c|c|c|c|c|c|c|c|c|c|}
\hline \multirow{4}{*}{ No. } & \multicolumn{4}{|c|}{ Coating characteristics } & \multicolumn{8}{|c|}{ Obtained results } \\
\hline & \multirow{3}{*}{$\begin{array}{c}\text { Coating } \\
\text { Description }\end{array}$} & \multirow{3}{*}{$\begin{array}{l}\text { Compo- } \\
\text { sition }\end{array}$} & \multicolumn{2}{|c|}{$\begin{array}{l}\text { Thermal } \\
\text { parameter } \\
\text { values }\end{array}$} & \multicolumn{4}{|c|}{$\begin{array}{c}\text { Effects achieved } \\
\text { on the laboratory stands }\end{array}$} & \multicolumn{4}{|c|}{ Effects achieved in the industry } \\
\hline & & & $\varepsilon_{\mathrm{T}}$ & $\lambda$ & without & & with & increase in & \multirow[b]{2}{*}{$\begin{array}{l}\text { Element } \\
\text { name }\end{array}$} & \multicolumn{2}{|c|}{ Obtained result, incl. } & \multirow[b]{2}{*}{$\begin{array}{c}\text { Industrial } \\
\text { plant }\end{array}$} \\
\hline & & & & $\mathrm{Wm}^{-1} \mathrm{~K}^{-1}$ & $\begin{array}{c}\text { coating } \\
\text { W }\end{array}$ & & $\begin{array}{l}\text { coating } \\
\text { W }\end{array}$ & $\begin{array}{l}\text { thermal } \\
\text { efficiency }\end{array}$ & & $\begin{array}{l}\text { Thermal } \\
\text { effects }\end{array}$ & $\begin{array}{l}\text { Durability / } \\
\text { no. of } \\
\text { campaigns }\end{array}$ & \\
\hline 1 & 2 & 3 & 4 & 5 & 6 & & 7 & 8 & 9 & 10 & 11 & 12 \\
\hline 1 & $\begin{array}{l}\text { Absorptive and } \\
\text { conductive }\end{array}$ & $\begin{array}{c}\mathrm{Cr}_{3} \mathrm{C}_{2}+ \\
25 \% \mathrm{NiAl}\end{array}$ & 0.75 & 30 & 9490 & & 173780 & $84 \%$ & $\begin{array}{c}\text { furnace roof } \\
\text { supporting } \\
\text { beams }\end{array}$ & $\begin{array}{c}30 \% \\
\text { increase } \\
\text { in steam } \\
\text { amount }\end{array}$ & $\begin{array}{c}3 \\
\text { campaigns }\end{array}$ & $\begin{array}{l}\text { Steelworks: } \\
\text { Łabędy } \\
\text { Zawiercie }\end{array}$ \\
\hline 2 & $\begin{array}{l}\text { Absorptive and } \\
\text { conductive }\end{array}$ & $\begin{array}{c}\mathrm{Cr}_{3} \mathrm{C}_{2}+ \\
25 \% \mathrm{NiAl}\end{array}$ & 0.75 & 30 & 9490 & & 17380 & $84 \%$ & $\begin{array}{c}\text { charging } \\
\text { door frames }\end{array}$ & $\begin{array}{c}30 \% \\
\text { increase } \\
\text { in steam } \\
\text { amount }\end{array}$ & $\begin{array}{c}3 \\
\text { campaigns }\end{array}$ & $\begin{array}{l}\text { Steelworks: } \\
\text { Łabędy } \\
\text { Zawiercie }\end{array}$ \\
\hline \multirow[t]{2}{*}{3} & $\begin{array}{c}\text { Absorptive and } \\
\text { conductive }\end{array}$ & $\begin{array}{c}\mathrm{Cr}_{3} \mathrm{C}_{2}+ \\
40 \% \mathrm{NiAl} \\
\end{array}$ & 0.86 & 20 & 10226 & & 15089 & $48 \%$ & $\begin{array}{c}\text { boiler } \\
\text { hopper }\end{array}$ & \multicolumn{2}{|c|}{ under operation } & $\begin{array}{c}\text { Betchatów } \\
\text { Power Plant }\end{array}$ \\
\hline & $\begin{array}{l}\text { Absorptive and } \\
\text { conductive }\end{array}$ & $\begin{array}{c}\mathrm{Cr}_{3} \mathrm{C}_{2}+ \\
40 \% \mathrm{NiAl}\end{array}$ & 0.86 & 20 & 10226 & & 15089 & $48 \%$ & $\begin{array}{c}\text { heat } \\
\text { treatment } \\
\text { furnace } \\
\text { crucible }\end{array}$ & \multicolumn{2}{|c|}{ under operation } & $\begin{array}{l}\text { ZPE Elterma } \\
\text { Świebodzin }\end{array}$ \\
\hline 4 & $\begin{array}{l}\text { Absorptive and } \\
\text { insulating }\end{array}$ & $\begin{array}{l}\text { int. } \mathrm{ZrO}_{2} \\
\text { out. } \mathrm{Cr}_{2} \mathrm{O}_{3}\end{array}$ & $-\overline{82}$ & $\begin{array}{l}1 \\
5\end{array}$ & $\begin{array}{c}\mathrm{t}_{\text {air }} \\
\mathrm{t}_{\text {burn. }}\end{array}$ & $\begin{array}{l}89^{\circ} \mathrm{C} \\
184^{\circ} \mathrm{C} \\
\end{array}$ & $\begin{array}{l}104^{\circ} \mathrm{C} \\
172^{\circ} \mathrm{C}\end{array}$ & $\begin{array}{c}23 \% \\
6 \%\end{array}$ & $\begin{array}{c}\text { recuperator } \\
\text { segment }\end{array}$ & \multicolumn{2}{|c|}{ under operation } & $\begin{array}{c}\text { Furnaces } \\
\text { Department, } \\
\text { Częstochowa }\end{array}$ \\
\hline
\end{tabular}

The $66.7 \%$ to $97.7 \%$ increase in the value of heat absorbed by water flowing in the system of tubes covered with the $\mathrm{Cr}_{2} \mathrm{O}_{3}+25 \% \mathrm{NiAl}$ coating causes the lowering of the combustion gas temperature, which leads to a decrease in the combustion gas volume and, in industrial installations, causes an increase in the dust concentration in the combustion gas volume and increases the amount of dusts precipitating in the dust collector through which the combustion gas flows.

The results obtained from the second stage of tests, which was carried out by combining the section $1(\mathrm{NiAl})$ with section $3\left(\mathrm{Cr}_{3} \mathrm{C}_{2}+40 \% \mathrm{NiAl}\right)$, proved to be less interesting from those obtained from the first stage. The greatest values of heat fluxes carried away with water were attained in the sixth measurement series (II.6). The obtained values of the heat fluxes carried away by water from the section of the exchanger covered with the $\mathrm{Cr}_{3} \mathrm{C}_{2}+40 \% \mathrm{NiAl}$ coating were by approx. $50 \%$ higher than the values of heat fluxes carried away with water flowing out of section 1 .

The use of cermet coatings made from the mixtures of oxides with NiAl 
proved to be positively less advantageous that the use of coatings made from the mixtures of the carbide with $\mathrm{NiAl}$.

The results obtained in the laboratory were confirmed in the full-scale operation of the supporting beams of furnace roofs and charging door frames. By spraying the radiated surfaces of these constructional elements of metallurgical furnaces, a few dozen percent increase in the steam amount an parameters (such as pressure) was obtained - Tab. 4, rows 1 and 2 .

\section{Conclusions}

1. Experimental studies have confirmed that both ceramic and cermet coatings with rough surface have great ability to heat absorption. The emissivity of the coatings decreases with the addition of a metal component to the ceramic material. It has been found at the same time that the emissivity of the metal coatings is above twice as high as the emissivity coefficient value for solid-state metals.

2. Examination of the effect of coatings sprayed on the elements of equipment operated in the laboratory showed:

- in the presence of the cermet coatings with high values of emissivity and heat conductance, the doubling of the amount of heat carried away by water flowing in the exchanger was obtained (Fig. 3, Tab. 3);

- in the presence of the bi-layer coating (composed of a low-conductivity inner layer and a high-emissivity outer layer), an increase in the heated air temperature and a decrease in the temperature of combustion gas leaving the model flue with an installed recuperator were obtained.

3. Values of the emissivity and thermal conductivity of the coatings have been found to correlate with relationship (1.b) and also with the values of heat fluxes absorbed by the heated media flowing in the model (Tab. 4) and industrial heat exchangers with coating applied on their surfaces (Tab. 5). 


\section{References}

[1] Morel S.: Thermal Spraying Coatings. Wyd. Politechniki Częstochowskiej, Częstochowa 1997.

[2] Hernas A.,Dobrzański J.: The Permanence and the Decay of Elements of Pots and Steam Turbines. Wyd. Politechniki Sląskiej, Gliwice 2003, 24-45.

[3] Sala A.: Radiation Heat Transfer. WNT, Warsaw 1982, 18-43.

[4] Burakowski T.,Wierzchoń T.: Engineering of the surface of metals. WNT, Warsaw 1995.

[5] Abrgmowicz B.G., Goldsztein W.E.: Intensification of the Exchange of the Warm Weather with Coatings. Eniergia, Moscow 1977, 26-39.

[6] Morel S.: Using plasma spraying coatings in the economy of the thermal mill. Przegląd Spawalnictwa 81(2009), 9, 90-93.

[7] Węgrzyn T., Piwnik J.: Low alloy welding with mocro-jet cooling. Arch. Metllurgy and Materials 57(2012), 2.

[8] Morel S.: Application of plasma-sprayed coatings in heat absorption by radiated walls. Arch. Energ. 41(2011), 3-4, 111-126.

[9] Morel S.: Using plasma covers in smelting heating devices. Hutnik-Wiadomości Hutnicze 78(2011), 5, 449-451.

[10] Hejwowski T.: Modern put thermal coatings wear-resistant abrasive and erosional. Wyd. Politechnika Lubelska, Lublin 2013.

[11] Hermas A., Chmiela B.: Untypical bromine corrosion in bolers co-firing biomass. J. AMME 54(2012), 1, 58-66.

[12] Bielikowski W.: Corrosion of the area exchanger of pots at slaniu low-emission. Energetyka 1(2000), 45-51.

[13] Zubielewicz M.: Directions of the research and development of protective coatings. Ochrona przed korozja 4(2006), 97-98. 